\title{
In-situ stress around source faults of seismic events in and beneath South African deep gold mines
}

\author{
Y. Yabe', S. Abe', T. Ito1, A. Ishida², K. Sugimura², M. Kanematsu' ${ }^{2}$, M. Higashi2, R. Tadokoro², \\ H. Ogasawara ${ }^{2}$, A. Funato ${ }^{3}$, H. Kato ${ }^{4}$, B. Watson ${ }^{5}$, S. Mngadi ${ }^{5}$, R. Durrheim ${ }^{5}$, \\ G. Hofmann ${ }^{6}$ and L. Scheepers ${ }^{6}$ \\ 1Tohoku University, Japan \\ 2Ritsumeikan University, Japan \\ ${ }^{3}$ Fukada Geological Institute, Japan \\ 43D Geoscience, Japan \\ ${ }^{5}$ University of the Witwatersrand, South Africa \\ ${ }^{6}$ Anglogold Ashanti, South Africa
}

To demonstrate the possibility of stress measurement at depths of more than $3 \mathrm{~km}$, in-situ stress states were determined around the source faults of three seismic events: a Mw2.2 seismic event at about $3.3 \mathrm{~km}$ below surface in Mponeng gold mine, a Mw3.5 seismic event at about $3.5 \mathrm{~km}$ below surface in the Savuka gold mine, and the Orkney earthquake (Mw5.5), with its hypocentre about $5 \mathrm{~km}$ below surface, beneath the Moab Khotsong gold mine.

The Mw2.2 seismic event occurred in a $30 \mathrm{~m}$ thick gabbroic dyke that intruded into a host rock of quartzite. A $90 \mathrm{~m}$ long borehole was drilled to penetrate its source fault. Borehole breakout and core discing were observed in the host rock and the hanging wall of the source fault, i.e., in the dyke. Diametrical core deformation analysis (DCDA) and deformation rate analysis (DRA) were applied to core samples retrieved from the borehole.

The DCDA determines the differential stress in the plane normal to a borehole by measuring the cross-section shape of a core sample, while the DRA reproduces the normal stress in the orientation in which a cyclic loading is applied, i.e., to obtain hysteresis of the stress-strain curves. By integrating these measurements and criteria of the borehole breakout and the core discing, the principal stress states in the host rock, the footwall in the dyke and the hanging wall in the dyke were reproduced. Significant differences were found between the stress states in the footwall and the hanging wall.

The Mw3.5 seismic event occurred in a $36 \mathrm{~m}$ thick dyke called BV78. A tunnel that was damaged by the seismic event passed through the source region. The compact conicalended borehole overcoring (CCBO) technique was applied at two sites along the tunnel; one site was in an area de-stressed by mining and the other about $10 \mathrm{~m}$ from the dyke in an area of increased stress owing to the mining abutment above. DCDA was also applied to the core samples.

Three boreholes (Hole A, Hole B and Hole C) that reach an aftershock area in the upper margin of the source fault of the Orkney earthquake (Mw5.5), were drilled by the ICDPDSeis project (Ogasawara et al, 2019). Since the holes were designed to be drilled in the direction of the maximum compression, borehole breakout or core discing rarely occurred. The DCDA was applied to core samples recovered from Hole A and Hole B. The DRA was also applied to core samples of Hole A. The differential and the normal stresses along Hole A showed a spatial variation that correlates with a variation in lithology and the aftershock distribution. 


\section{INTRODUCTION}

The stress state in a rock mass provides essential information for evaluating the stability of an underground structure and optimally design the mining procedure to minimise rock burst hazard. A variety of methods to measure stresses has been described in literature. They can be classified into four categories based on their measurement procedures: active on-site method, passive on-site method, active laboratory method and passive laboratory method. The hydrofracturing test (HFT) and overcoring (OC) are typical active on-site methods. A common passive on-site method is the analysis of borehole breakout (BB). The stress memory of rocks can be reproduced by active tests in a laboratory, such as the deformation rate analysis (DRA). The diametrical core deformation analysis (DCDA) and the analysis of core discing $(\mathrm{CD})$ are passive laboratory methods.

The individual methods mentioned above have their own advantages and limitations for deep mining. For example, theoretical backgrounds of the HTF and the OC are clear. However, in the case of the HFT, it is difficult to confine the high water pressure of about $100 \mathrm{MPa}$ required to induce fractures on the borehole wall. The OC is hard to apply to a borehole at greater depths. The analysis of the BB and the DCDA can only provide information about the stresses in the plane normal to the borehole. Estimation of stresses from the $\mathrm{CD}$ do not require additional measurements or observation, its results strongly depend on an assumption of the normal stress along the borehole and the normal pressure applied at the drill tip during drilling (Watson et al, 2006). Though the DRA can be applied to core samples recovered from a deep hole, the largest stresses that can be measured by this method are limited by the uniaxial strength of the samples. Therefore, it is important to integrate a variety of methods to obtain a reliable estimation of the in-situ stresses at depths deeper than $3 \mathrm{~km}$.

The ICDP-DSeis (Drilling into seismogenic zones of M2.0-M5.5 earthquakes in deep South African gold mines) project is an international project promoted under a collaboration among researchers in the fields of geophysics, geology, geochemistry, geomicrobiology and rock engineering from seven countries; these include Japan and South Africa. Three source faults of M2.2-5.0 seismic events and earthquake at depths of $3 \mathrm{~km}$ or deeper were intersected by this project to recover rock samples from the source areas (See Figure 1). In this study, we analysed boring core samples obtained by the ICDP-DSeis project to demonstrate how the above-mentioned techniques can work to reconstruct the stress states at such great depths.

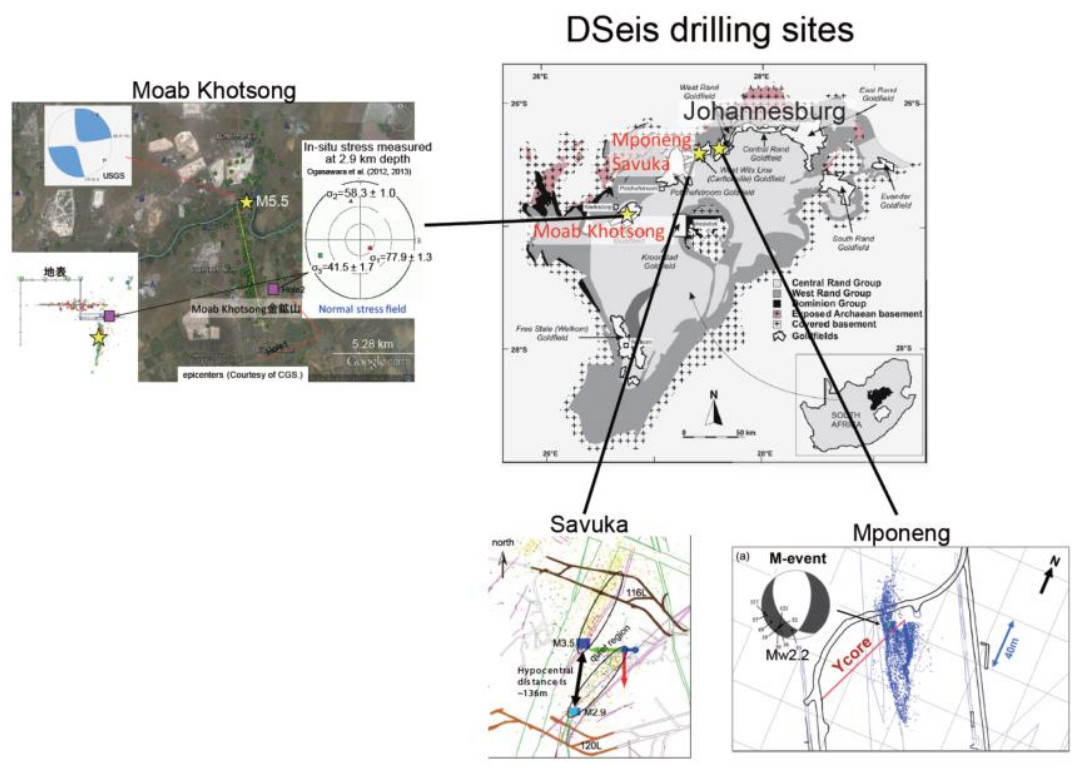

Figure 1. Locations of stress measurement sites in this study and seismicity at each site 


\section{METHODS}

Analyses of borehole breakout (BB) and core discing (CD)

An occurrence criterion of the BB was given by Zoback et al (1985) and Barton et al (1988) as follows:

$$
U C S \leq 3 \sigma_{x}-\sigma_{y}-P
$$

where $\sigma_{x}$ and $\sigma_{y}$ are the maximum and the minimum compression, respectively, in the plane normal to the borehole and $P$ is pore pressure. Note that compression is taken to be positive in this study. Because water is drained from faults and joints in South African gold mines before mining operation is commenced, it is assumed that $P=0$ in this study. The occurrence of $\mathrm{BB}$ is determined from the observation of the borehole wall by an optical or an acoustic televiewer.

Occurrence criteria for CD proposed by Kaga et al (2003) and Matsuki et al (2004) are expressed by

$$
\begin{aligned}
& U T S=-A \sigma_{m}+B \sigma_{x}-D\left(\sigma_{x}-\sigma_{y}\right) \\
& -\sigma_{y}+\frac{19}{11} \sigma_{z} \leq \sigma_{x} \leq 17 \sigma_{y}-7 \sigma_{z}
\end{aligned}
$$

where coefficients $A, B$ and $D$ are functions of the disc thickness, $\sigma_{z}$ is the normal stress along the borehole, and $\sigma_{m}$ is the average of $\sigma_{x}, \sigma_{y}$ and $\sigma_{z}$. In this study, thicknesses of $\sim 10$ discs in each section of continuous occurrence of the core discing were averaged to determine the coefficients $A, B$ and $D$.

\section{Deformation rate analysis (DRA)}

The DRA was proposed by Yamamoto et al (1990) to reproduce the stress memory of a rock from the hysteresis of stress-strain curve under cyclic uniaxial loading. The hysteresis is evaluated by the strain difference function $\Delta \varepsilon_{i, j}(\sigma)$ defined by

$$
\Delta \varepsilon_{i, j}(\sigma)=\varepsilon_{j}(\sigma)-\varepsilon_{i}(\sigma), j>i
$$

where $\sigma$ is the applied axial stress and $\varepsilon_{i}(\sigma)$ is the axial strain for i-th loading. The stress memory is detected from the bending of this function, which is a discontinuous change in the gradient of the strain difference function. In this study, five cyclic loading-unloading tests were conducted to obtain the strain difference functions. Details of the DRA are described in Yamamoto et al (1990), Sato et al (2003), Yabe et al (2008), Yamamoto (2009), Yabe et al (2010), and Yabe and Omura (2011).

\section{Diametrical core deformation analysis (DCDA)}

In the DCDA, the differential stress in the plane normal to a borehole is estimated from an azimuthal variation in diameter of a boring core sample (Funato and Ito, 2017). It is assumed that the core sample expands elastically in response to a stress relief when the core is cut from the rock mass by boring. The azimuthal variation in diameter of the expanding core can be expressed by

$$
d(\theta)=\frac{d_{\max }+d_{\min }}{2}+\frac{d_{\max }-d_{\min }}{2} \cos 2(\theta-\alpha)
$$

where $d(\theta)$ is core diameter at an azimuth $\theta, d_{\max }$ and $d_{\min }$ are the maximum and the minimum diameter, respectively, of the core sample and $\alpha$ is the azimuth of $d_{\max }$. The differential stress in the plane normal to the borehole can be deduced from the maximum and the minimum diameter of the core sample by

$$
\sigma_{x}-\sigma_{y}=\frac{d_{\max }-d_{\min }}{d_{0}} \frac{E}{1+v} \approx \frac{d_{\max }-d_{\min }}{d_{\min }} \frac{E}{1+v}
$$

where $E$ and $v$ are Young's modulus and Poisson's ratio, respectively. The variable $d_{0}$ represents diameter of the core sample before it expands in response to the stress relief. Since it is impossible to 
know $d_{0}$ with such a high accuracy as its expansion $(\sim 1 \mu \mathrm{m})$ in most cases, Funato and Ito (2017) assumed that $\left(d_{\min }-d_{0}\right) \ll d_{0}$ and that $\frac{d_{\max }-d_{\min }}{d_{0}}$ can be replaced by $\frac{d_{\max }-d_{\min }}{d_{\min }}$.

We measured diameters of each core sample every $2^{\circ}$ along 4 or more profile lines separated by $\sim 2 \mathrm{~cm}$. The theoretical curve (eq. 5) was fitted to the average azimuthal variation in diameter to estimate $d_{\text {max }}$ and $d_{\min }$. Because the boring cores were not oriented, the orientation of the maximum compression could not be determined, but only magnitude of the differential stress was obtained.

\section{Compact conical ended borehole overcoring (CCBO)}

The CCBO is an overcoring technique developed by Sakaguchi et al (1992), Sugawara and Obara (1999) and Ogasawara et al (2013) to measure the stress state in a rock mass by a single drilling. The borehole bottom is converted into a conical shape. A conical strain-cell by which 16 strain components can be measured is attached (glued) to the conical bottom after confirming that there is no damage. Then, the borehole is extended by a thin-walled drilling bit to carry out the overcoring. The strain change associated with the stress relief during overcoring is measured by the strain cell from which the in-situ stress can be calculated. The elastic properties that are needed for the calculation of the stress state can be obtained from the boring core sample recovered by overcoring.

\section{RESULTS}

A seismic event of Mw2.2 occurred on 27 December 2007 at a depth of about $3.3 \mathrm{~km}$ in Mponeng mine. Aftershocks of the seismic event, that were recorded by a high-sensitive seismic network operated by the JAGUARS project (Nakatani et al, 2008) clearly delineated an oblique plane in a gabbroic dyke on which the hypocenter of the seismic event was determined. A $90 \mathrm{~m}$-long borehole that was designed to intersect with the oblique plane at a distance about $70 \mathrm{~m}$ from hole collar was drilled about 1.5 years after the occurrence of the seismic event (Yabe et al, 2013). Severe damage on the borehole wall were found by an optical televiewer at a distance of about $69 \mathrm{~m}$ from hole collar. This confirmed that the oblique plane was the source fault of the seismic event. Based on the rock types and locations relative to the source fault, the source area is divided into three sections: the host rock (quartzite) of the gabbroic dyke, the footwall in the dyke (dyke-footwall), and the hangingwall in the dyke (dyke-hangingwall).

CD occurred along the boring cores at some depths in the host rock and the dyke-footwall sections (See Figure $2 \mathrm{~b}$ ). For the first $10 \mathrm{~m}$ of the dyke-hangingwall, the borehole cores were severely damaged and only debris with particle sizes of less than $10 \mathrm{~mm}$ were recovered. Continuous CD was seen in the rest of the $10 \mathrm{~m}$ section of the dyke-hangingwall. The uniaxial tensile strength (UTS) was measured by the Brazilian test to be between $20 \mathrm{MPa}$ and $21 \mathrm{MPa}$ for both rock types of the host rock and the dyke.

Borehole breakout was observed in some places along the borehole wall in the host rock by an optical televiewer (See Figure 2a). It rarely occurred in the dyke-footwall except for a section in a thick calcite vein. For the first $10 \mathrm{~m}$ of the dyke-hangingwall section, where the borehole core was crushed, the borehole breakout was observed to be continuous. The borehole wall of the last $10 \mathrm{~m}$ was relatively intact. Except for the region close to the source fault, the orientations of borehole breakout were rotated counterclockwise by about $20^{\circ}$ from horizontal in all rock types. However, it should be noted that the resolution of the televiewer was low and the accuracy of BB azimuth was as low as about $10^{\circ}$. The UCS of the host rock and the dyke is $183 \mathrm{MPa}$ and $330 \mathrm{MPa}$, respectively.

The DCDA was applied to 21 core samples. However, data with a good signal-to-noise ratio could only be obtained from 12 core samples (4 in the host rock, 7 in the dyke-footwall, 1 in the dyke-hangingwall, Figure 2c). Elastic moduli were evaluated from stress-strain curves obtained by the uniaxial compression test for the UCS measurements. The Young's modulus of the host rock and the dyke is $75 \mathrm{GPa}$ and $81 \mathrm{GPa}$, respectively. The Poisson's ratio for the two rock types is 0.14 and 0.18 , respectively. 


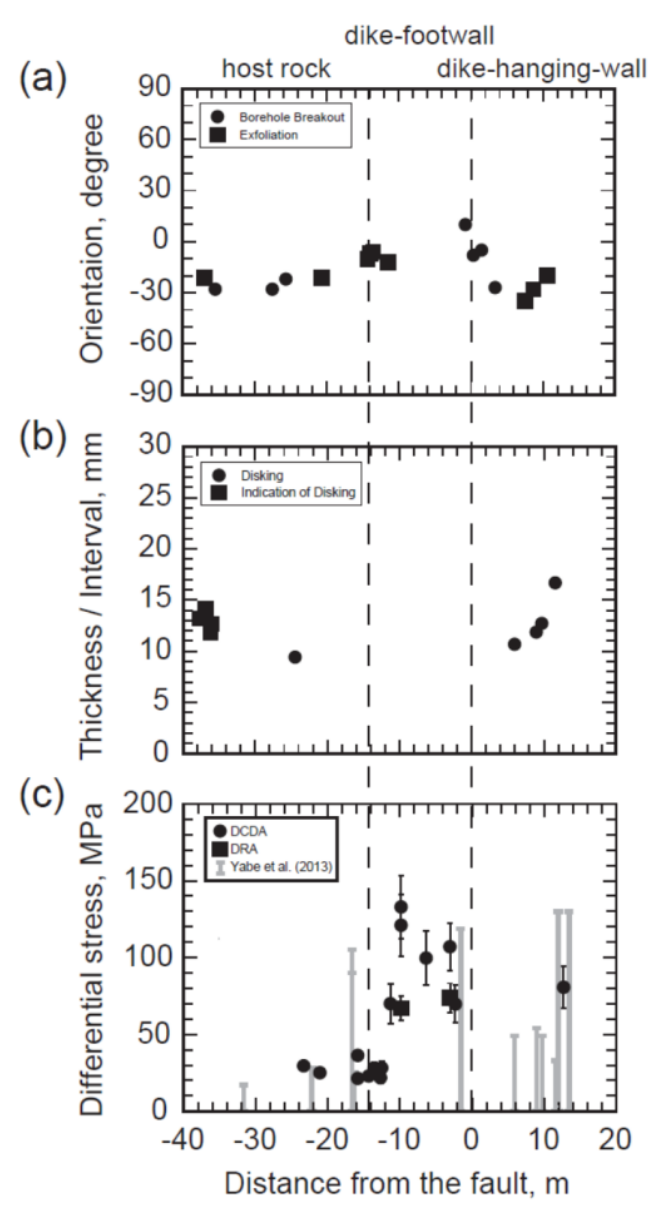

Figure 2. Spatial variations of (a) orientation of the $B B$, (b) thickness of the $C D$, and (c) the differential stress measured by the DCDA and the DRA with respect to distance from the fault of Mw2.2 seismic event. The orientation of the borehole breakout is measured counter-clockwise from horizontal.

The DRA was carried out on core samples recovered from distances of $59 \mathrm{~m}$ and $68 \mathrm{~m}$ from hole collar in the dyke-footwall section (See Figure 2c). Magnitudes of normal stress in four directions (every $45^{\circ}$ ) in the plane normal to the borehole, as well as the normal stress parallel to the borehole were determined. At least 2 specimens were tested for each direction.

Under an assumption that the stress state in each section of the host rock, the dyke-footwall or the dykehangingwall is uniform, a grid-search was carried out to find the principal stress state not only reproducing the differential stresses and the normal stress obtained by the DCDA and DRA, but also satisfying the occurrence criteria of the $\mathrm{CD}$ and the $\mathrm{BB}$. The orientation of $\mathrm{BB}$ on the borehole wall and the slip direction of the Mw2.2 seismic event were also considered to constrain the principal stress state.

The estimated principal stress state in each section is shown in Figure 3. The principal directions in the host rock and in the dyke-hangingwall are similar to those of the virgin stress state measured by the CCBO at a site less affected by mining in the same mine (Ogasawara et al, 2012). However, the maximum stress axis in the dyke-footwall leans to the south. The minimum stress axis is rotated clockwise by $\sim 45^{\circ}$ from that in the host rock.

The vertical stress $\left(q_{v}\right.$ in $\mathrm{MPa}$ ) before mining in gold mines in South Africa can be estimated from a standard stress model (Jager and Ryder, 1999); 


$$
q_{v}=0.027 h
$$

where $h$ is the depth from the ground surface in metres. Therefore, the vertical stress at our site $(h \sim 3300 \mathrm{~m})$ is predicted to be $89 \mathrm{MPa}$. However, our measurements showed that the vertical stresses in the host rock, the dyke-footwall and the dyke-hangingwall are as high as $\sim 140 \mathrm{MPa}, \sim 100 \mathrm{MPa}$ and $\sim 180$ $\mathrm{MPa}$, respectively, and about $140 \mathrm{MPa}$ on average. A higher density of the dyke may contribute to increase the vertical stress in our site, while it is not enough to justify the increase by 50MPa. Because the dyke does not bear the gold reef, it was left un-mined as a dip pillar. The overburden weight above the excavated area concentrates to the dyke. As a result, the vertical stress in and around the dyke below the excavated area would be increased. Ogasawara et al (2014) observed $10 \mathrm{MPa}$ and $20 \mathrm{MPa}$ increase in sub-vertical compression in the host rock and the dyke-footwall, respectively, during a period from May to December 2007, i.e., for a period of 8 months before the Mw2.2 seismic event. Mining had taken place above the site a few years before the observation. Therefore, the larger vertical stress along the borehole by about $50 \mathrm{MPa}$ on average than the standard model, can be understood to be caused by the mining about $90 \mathrm{~m}$ above the site.

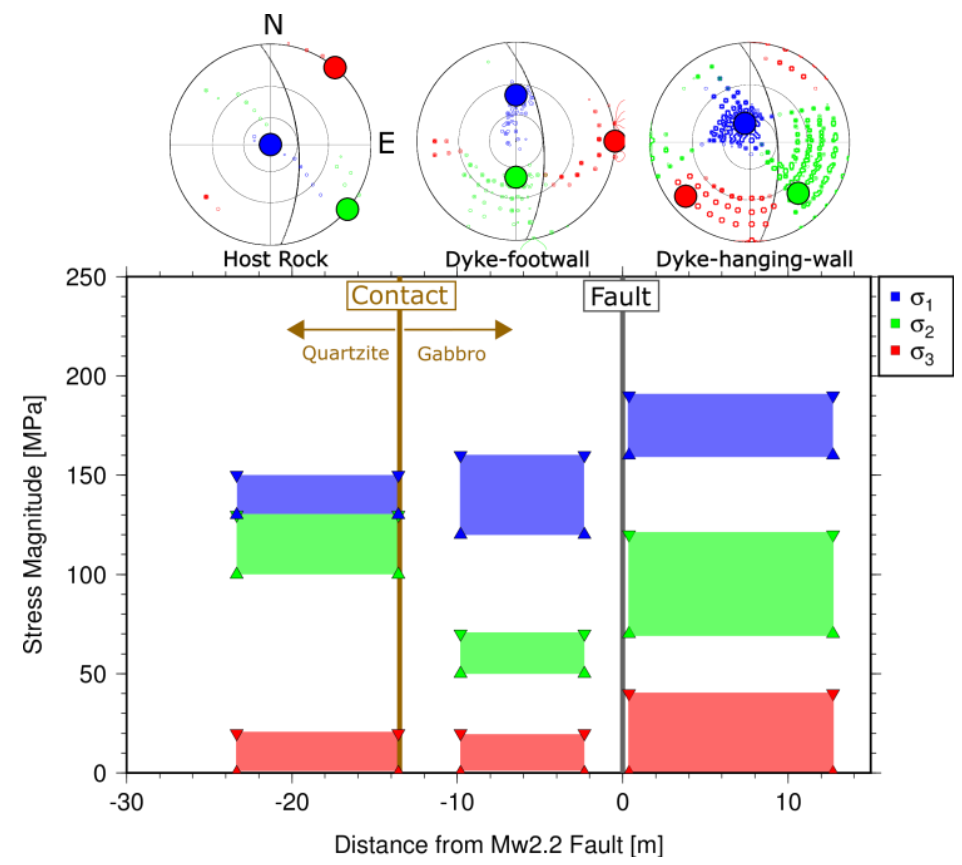

Figure 3. The principal stress state in each section estimated by the grid-search. Lower-hemisphere projections on top represent the principal stress direction in individual sections (left: the host rock, middle: the dykefootwall, right: the dyke-hangingwall). Large circles are the robust estimation and small circles are acceptable directions. The fault plane of the Mw2.2 seismic event is indicated by a black line. Lower plot shows possible magnitude ranges of the principal stress in each section. Blue, green and red colours represent the axis or the magnitude range of the maximum, the intermediate and the minimum principal stress, respectively.

\section{CCBO stress measurements in the source region of an M3.5 seismic event}

As part of the rock mechanics investigations following the Mw3.5 seismic event on 29 April 2016, the CCBO measurements were conducted as close as possible to the BV78 dyke on 116 Level, in which the seismic event occurred. This method had been successfully applied many times before in the neighbouring mine of Tau Tona. It was attempted firstly to do a measurement in a de-stressed area near the dyke, and secondly in the high-stress area near the BV78 dyke, to compare and validate results from these different stress environments.

Furthermore, a static elastic boundary element numerical model (Map3D) of the mine was set up and used to optimise drilling direction (to minimise the potential for failure) and also to quantify the 
expected tectonic and mining-induced stress state. The stress state of Hofmann et al (2013) was used, where reasonable results were obtained for the pre-mining stress state for a larger area including Tau Tona and Mponeng mines. This was based on the CCBO stress measurements away from large mining spans.

Three boreholes were drilled where the CCBO method was applied successfully (See Figure 4). Figure 4 also shows the tabular mining outlines, and the probable fault slip area (Van Aswegen, 2017). These sites are discussed below in more detail together with the modelling results. All measured and modelled stress states are depicted in Figure 5.

a)

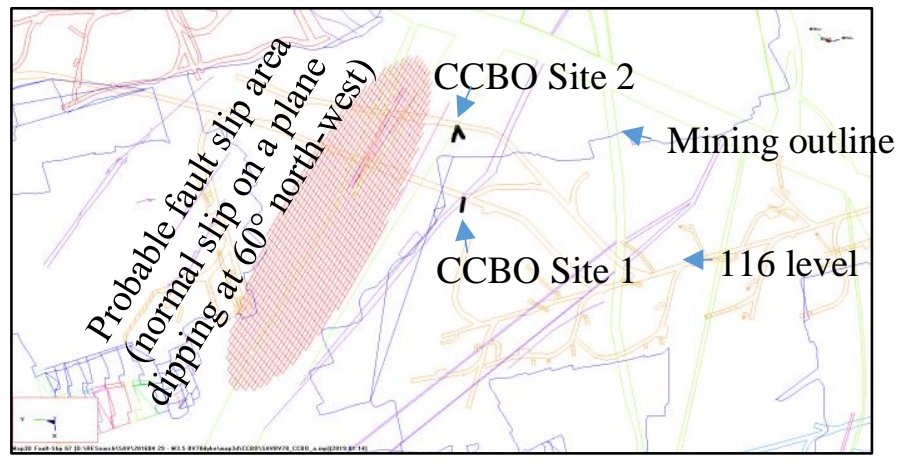

b)

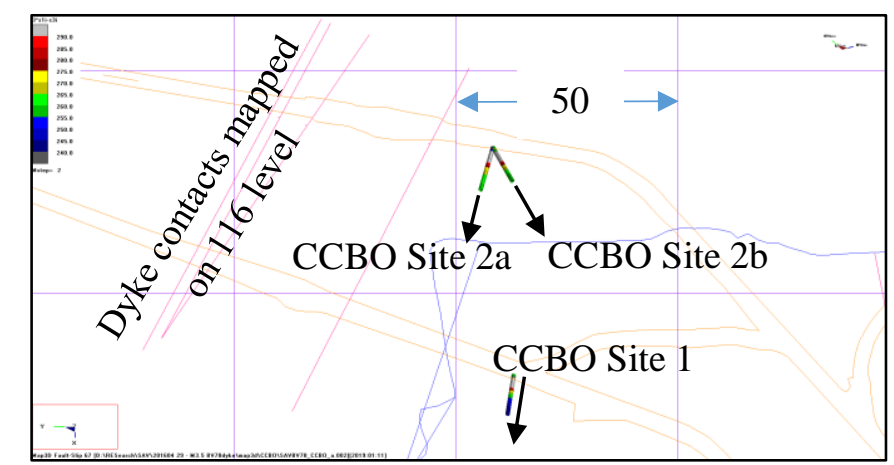

Figure 4. (a) Plan view of the BV78 dyke area and locations of the CCBO stress measurements on 116 level. Geological interpretations are shown for on-reef as well as on 116 level. The probable fault slip area associated with the M 3.5 seismic event are shaded. (b) Zoom-in view of the above, showing the three CCBO drill-holes in more detail. A scale is also shown from which approximate distances can be derived.

\section{Site 1 - tunnel supposedly destressed by overlaying mining}

Three CCBO measurements were done on 13, 14 and 15 September 2016, at borehole depths of $10.85 \mathrm{~m}$, $11.27 \mathrm{~m}$ and $11.58 \mathrm{~m}$, respectively. As can be seen in Figure 4, this location on 116 level was about $56 \mathrm{~m}$ below mining, and at a depth of $3360 \mathrm{~m}$ below surface. The pilot hole inclined at $35^{\circ}$ upwards.

Strain relief curves with ultimate strains (not shown here) were very clear for all 48 strain gauges (i.e., three $\mathrm{CCBO}$ measurements with 8 transverse and 8 radial gauges each), and they agreed well with the theoretical curves for stress measurement. The standard deviation was determined to be less than $0.5 \mathrm{MPa}$ from the statistical fit, and therefore all indications are that the measurement result is reliable.

Interestingly, the result is very different from the modelled stress state, as shown in Figure 5, denoted by 'Site 1 '. The major and intermediate components are much lower than the modelled values, with $\sigma_{1}$, $\sigma_{2}$ and $\sigma_{3}$ measured as $40.2 \mathrm{MPa}, 18.2 \mathrm{MPa}$ and $10.5 \mathrm{MPa}$, respectively. Furthermore, the orientation of the principal stresses are significantly different, especially the intermediate and minimum components. 
The orientation of $\sigma_{1}$ agrees in terms of azimuth, although measured to be more horizontal $\left(17^{\circ}\right)$.

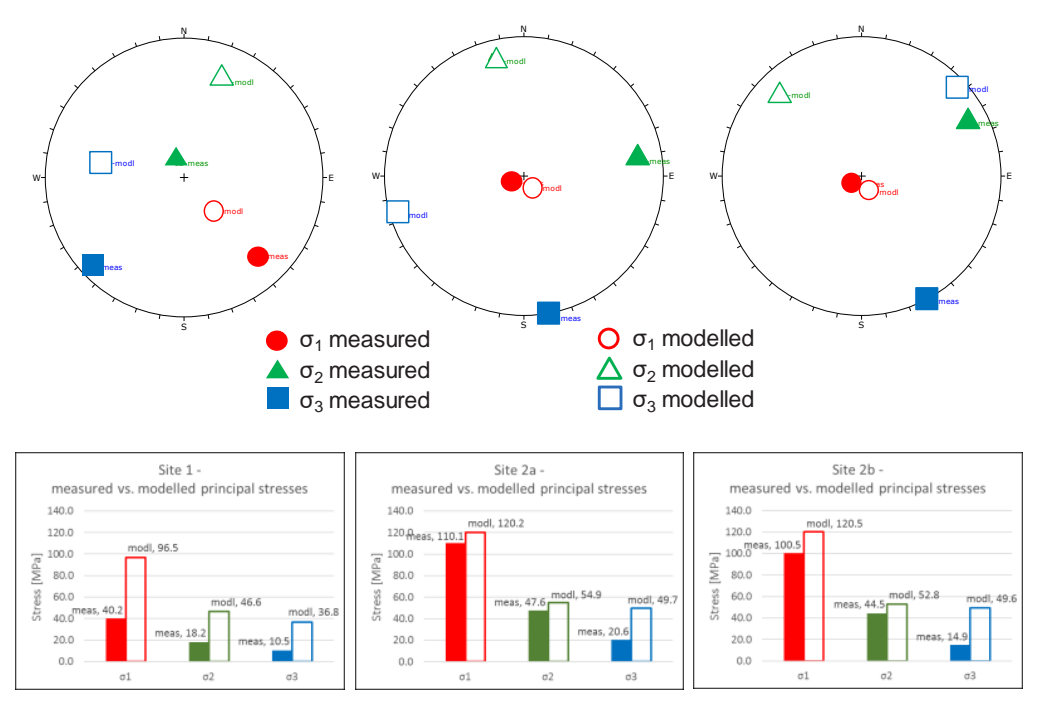

Figure 5. The CCBO stress measurement results compared with expected results from the elastic numerical model. The three sites, viz. 'Site 1', 'Site $2 a$ ' and 'Site $2 b$ ' are shown in Figure 4, see text for more descriptions of the drill-holes. Measured versus modelled values are indicated by the solid and open symbols, respectively.

Site $2 a-10 m$ from the dyke east contact, drilling perpendicularly into the tunnel sidewall On 28 March 2017, the first CCBO attempt was done at a depth of $10.3 \mathrm{~m}$, again at an inclination of $35^{\circ}$. Strain relief curves were not good. Borehole camera footage (prior to the overcoring) did reveal some breakout failure as well as scaling at the conic shape hole end, which evidently caused the strain gauges to behave non-linearly. This suggested relatively high stress levels and hence lower chance of successful overcoring.

The hole depth was advanced to $10.68 \mathrm{~m}$, which again revealed fracturing. Advancing the depth to $10.76 \mathrm{~m}$ indicated better conditions, and overcoring was attempted. Strain relief curves were good, and the ultimate strain of 16 gauges agreed well with the theoretical curves. The stress measurement result is denoted by Site 2a in Figure 5.

The hole was advanced twice, each time observing failure. Another CCBO attempt at $11.32 \mathrm{~m}$ again did not yield good results, and it was decided to abandon the hole.

Site $2 b-10 m$ from the dyke contact, with drilling direction optimised to minimize failure

The drilling direction was adjusted to be more in-line with the likely $\sigma_{1}$ field stress direction, to reduce the in-plane circular hole tangential stress and hence to reduce the potential for failure. The drilling inclination cannot be too steep due to the practical limitation of the weight of equipment to be manhandled. An inclination of $40^{\circ}$ was manageable, and the azimuth was chosen in a more easterly direction, i.e., at an angle of $50^{\circ}$, with the tunnel sidewall.

For this drilling direction, from the same drill rig platform, successful CCBO measurement was achieved at depths of $8.81 \mathrm{~m}, 9.13 \mathrm{~m}$ and $9.38 \mathrm{~m}$, on 19, 20 and 21 April 2017, respectively. Ultimate strains were determined clearly for all 48 strain gauges, yielding a statistical error of less than $1 \mathrm{MPa}$.

This result is denoted by Site $2 \mathrm{~b}$ in Figure 5, correlating well with Site 2a, also indicating that the result is reliable. (keeping in mind that Site $2 \mathrm{~b}$ was a shorter hole and at an angle to the tunnel, hence closer to the tunnel). In this case, measured $\sigma_{1}$ and $\sigma_{2}$ agreed fairly well with the modelled values in terms of magnitude and orientation, and the $\sigma_{1}$ orientation was similarly sub-vertical. The measured minimum principal stress component is significantly lower than the modelled value, suggesting a much lower 
than expected $k$-ratio in the tabular orebody dip direction (Trend of $160^{\circ}$ ). Regarding the magnitudes of modelled $\sigma_{2}$ and $\sigma_{3}$, they were similar, and hence their orientations could be interchanged. The orientation and the low magnitude of measured $\sigma_{3}$ suggest that a lower $k$-ratio assumption in the orebody dip-direction is applicable in the numerical model.

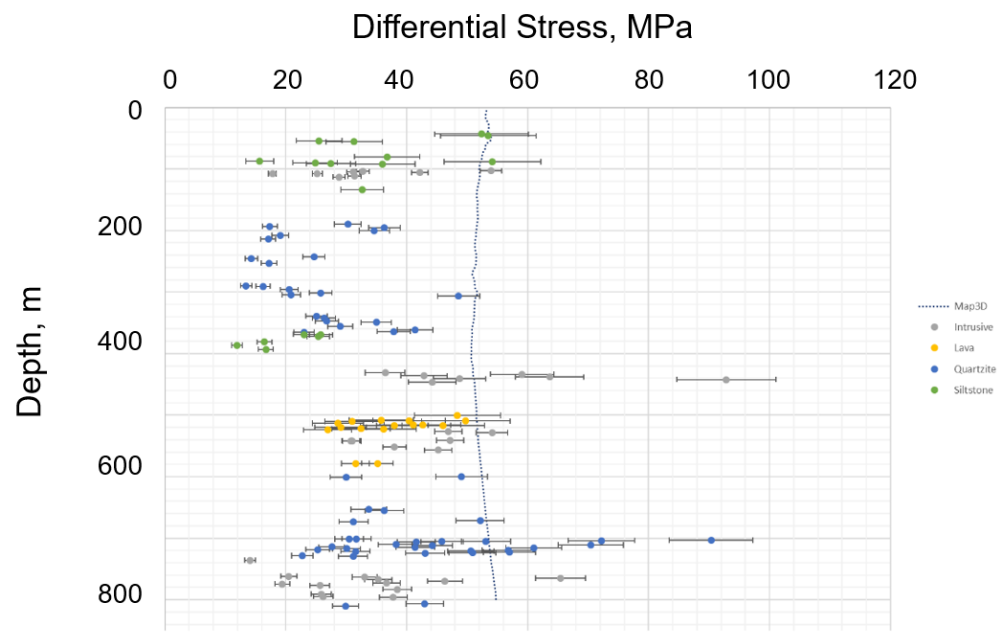

Figure 6. Depth dependence of the differential stress in the plane normal to the Hole A in the Moab Khotsong mine measured by the DCDA (solid circles with error bar) and that predicted by the numerical modelling (dashed line).

Stresses in the source region of the Orkney earthquake (M5.5)

The Orkney earthquake (Mw5.5) occurred on 5 August 2014 beneath the Moab Khotsong mine. Its hypocentre was located at a depth of about $5 \mathrm{~km}$ below surface. The aftershocks showed a vertical planar distribution that coincided with a nodal plane of the strike-slip focal mechanism solution of the Orkney earthquake. The shallowest aftershocks were several hundred metres below the mining horizon of the Moab Khotsong mine. Two holes (Hole A and Hole B) were drilled from one of the deepest tunnels in the mine to target the upper margin of the aftershock cluster. Hole A was drilled to a length of about $800 \mathrm{~m}$, but did not reach the aftershock cluster due to deflection of the hole. Hole B successfully intersected the aftershock cluster at a depth of about $600 \mathrm{~m}$ as measured along the hole. The borehole cores were fully recovered from both holes except for an approximately $10 \mathrm{~m}$ section in Hole B at a depth corresponding to the aftershock cluster.

The DCDA was applied to the borehole cores to investigate variations in the differential stress with depth (See Figure 6). Along Hole A, the differential stresses were between $10 \mathrm{MPa}$ and $40 \mathrm{MPa}$ at a depth between $200 \mathrm{~m}$ and $400 \mathrm{~m}$. These differential stresses increased to between $20 \mathrm{MPa}$ and $60 \mathrm{MPa}$ below the depths of $400 \mathrm{~m}$. There were two impulsive peaks with stresses as high as $90 \mathrm{MPa}$ at depths of about $440 \mathrm{~m}$ and $700 \mathrm{~m}$. The shallower peak coincided with a peak of the natural gamma ray intensity measured by in-hole logging. Welling of high salinity water was also observed at this depth. The deeper peak coincided with the depth of the shallowest aftershocks, though the Hole A did not intersect the aftershock cluster. To provide further constraint on the stress state, the normal stress along the borehole was evaluated by the DRA (See Figure 7). The results of this investigation showed stress levels of between $60 \mathrm{MPa}$ and $80 \mathrm{MPa}$ at depths of between $100 \mathrm{~m}$ and $500 \mathrm{~m}$ with a locally higher stress of about $110 \mathrm{MPa}$ at a depth of about $440 \mathrm{~m}$, where the differential stress also showed the impulsive peak. The numerical modelling provided the upper limit of the differential stress and the lower limit of the normal stress, but did not predict the impulsive peaks. 


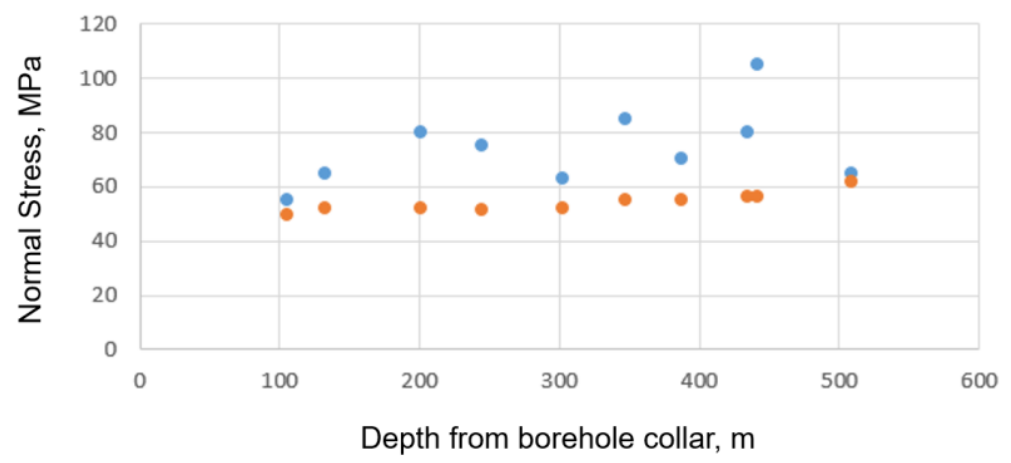

Figure 7. Depth dependence of the normal stress along borehole axis of the Hole A in the Moab Khotsong mine measured by the DRA (blue solid circles) and predicted by the numerical modelling (orange solid circles).

\section{DISCUSSIONS AND SUMMARIES}

This study demonstrates that stresses in a rock mass can be measured by the DCDA, DRA and the CCBO at depths greater than $3 \mathrm{~km}$. Individual techniques have their own advantages and disadvantages. For example, the ССВО can determine the principal stress state even by a single measurement, while the measurement point is limited within $10 \mathrm{~m}$ to $15 \mathrm{~m}$ from a tunnel and should be drilled in a direction close to the major principal stress. When intact borehole cores are recovered, the DCDA and the DRA can evaluate stresses away from the tunnel. The stress measurement by the DCDA is time efficient as it takes only 20 - 30 minutes for each point. However, it can provide only the differential stress in the plane normal to the borehole. We need to measure the differential stresses by using borehole cores recovered from multiple boreholes with different directions to reconstruct the principal stress state; but at a high cost. Although the DRA can reconstruct the principal stress state by using borehole cores recovered from a single borehole, it takes a lot of time to prepare the test specimens and measurements. It is therefore recommended that the DCDA and the DRA methods be applied to the same borehole cores for time and cost efficiency.

The stress state in a rock mass has been found to be significantly altered by the stress redistribution and transfer associated with mining and seismic events. The spatial variations in magnitudes of stresses can be as significant as several tens of MPa within a relatively short distance of a few tens of metres. In the case of the CCBO measurement in the source region of the M3.5 seismic event in Savuka mine, the measurement results were compared to an elastic numerical model. Though it is beyond the scope of this paper to investigate in detail the measured versus modelled stress tensors, some comments are made.

At Site 2 in Savuka mine, subject to the minimum $k$-ratio assumption in the numerical model, the measured stress agrees with the modelled stress, suggesting the applicability of the elastic stress model in this environment.

An important derivation is that the $k$-ratio in the tabular orebody dip-direction was measured to be significantly lower than the value in the model. Considering the major geological structure with the associated M3.5 seismic event, two possible explanations can be offered: (1) the pre-mining stress state was altered due to the dyke intrusion, or (2) the seismic event rupture itself caused a significant stress change in the surrounding rock mass.

At Site 1 in Savuka mine, stress was measured to be much lower and also at a different orientation than the model. The reason may be the same as one of the possibilities described above, but alternatively may be due to inelastic rock mass behavior playing a larger role than anticipated, especially at the 
tabular mining abutments.

Although the stress measurement site in Mponeng mine is also in the tabular mining abutment, the vertical stress was larger than that of the pre-mining stress state. This is in contrast with the Site 1 in Savuka mine, suggesting that the stress state is sensitive to the location of the measurement site in relation to the mining abutment, probably due to the extent of inelastic rock mass behavior at that site.

More advanced numerical modelling, including detailed geology, non-linearity and dynamic rupturing effects, may yield more insights. The stress measurement results do, however, suggest that stress levels around major dyke structures can be different to that predicted by elastic numerical models, whether before or after a seismic event, and that valuable information can be gained by applying stress measurement methods that are time- and cost-effective as those described above. These comments should not be specific for the sites in Savuka and Mponeng mines, but would suggest general tendencies of stress state in and around the dykes and the seismic event sources in deep mines.

\section{ACKNOWLEDGEMENT}

The authors wish to thank AngloGold Ashanti for providing the research site in Mponeng mine. This study was also supported by the International Continental Scientific Drilling Program (ICDP); JSPSNRF bilateral research project; SATREPS; JSPS Core-to-Core programme; Grant-in-Aid for Scientific Research; Earthquake Research Institute cooperative research programme; Tohoku University's 21st Century COE programme; Ritsumeikan University; the Ministry of Education, Culture, Sports, Science and Technology (MEXT) of Japan, under its Earthquake and Volcano Hazards Observation and Research Programme; and the DST-NRF South African Research Chair Initiative (SARChI).

\section{REFERENCES}

Barton, C. A., Zoback, M.D. and Burns, K. L. 1988. In-situ stress orientation and magnitude at the Fenton Geothermal site, New Mexico, determined from wellbore breakouts, Geophys. Res. Lett., 15, 467470 .

Funato, A. and Ito, T. 2017. A new method of diametrical core deformation analysis for in-situ stress measurements, Int. J. Rock Mech. Min. Sci., 91, 112-118, doi:10.1016/j.ijrmms.2016.11.002.

Hofmann, G., Scheepers, L. and Ogasawara, H. 2013, Loading conditions of geological faults in deep level tabular mines. Proceedings of the 6th Int. Symp. on In-Situ Rock Stress (RS2013), Sendai, Japan.

Jager, A. J. and Ryder, J. A. 1999. A handbook on rock engineering practice for tabular hard rock mines, The Safety in Mines Research Advisory Committee (SIMRAC), Johannesburg.

Kaga, N., Matsuki, K. and Sakaguchi, K. 2003. The in situ stress states associated with core discing estimated by analysis of principal tensile stress, Int. J. Rock Mech. Min. Sci., 40, 653-665.

Matsuki, K., Kaga, N., Yokoyama, T. and Tsuda, N. 2004. Determination of three dimensional in situ stress from core discing based on analysis of principal tensile stress, Int. J. Rock Mech. Min. Sci., 41, 1067-1190.

Nakatani, M., Yabe, Y., Philipp, J., Morema, G., Stanchits, S., Dresen, G. and JAGUARS Group.2008. Acoustic emission measurements in a deep gold mine in South Africa-Project overview and some typical waveforms, Seismol. Res. Lett., 79, 311.

Naoi, M., Nakatani, M., Yabe, Y., Kwiatek, G., Igarashi, T., Plenkers, K. 2011. Twenty thousand aftershocks of a very small (M2) earthquake and their relation to the mainshock rupture and geological structures, Bull Seism Soc Am, 101, 2300-2407, doi:10.1785/0120100346. 
Okada, Y. 1992. Internal deformation due to shear and tensile faults in a half-space, Bull. Seism. Soc. Am., 82, 1018-1040.

Ogasawara, H., Kato, H., Hofmann, G., and De Bruin, P. 2012. Trial of the BX conical-ended borehole overcoring stress measurement technique, J. SAIMM, 102, 749-754.

Ogasawara, H., Kato, H., Hofmann, G., Roberts, D., Piper, P, Clements, T., Yabe, Y. and Sakaguchi, K. 2013. In-situ stress measurements to constrain stress and strength near seismic faults in deep level South African gold mines. 6th International Symposium on In-Situ Rock Stress (RS2013), Sendai, Japan.

Ogasawara, H., Katsura, T., Hofmann, G., Yabe, Y., Ishii, H., Roberts, D., Nakao, S., Okubo, M., Ward, A. K. and Kawakata, H. 2014. The Ishii strainmeters to in-situ monitor rock mass response to mining in South African gold mines, in Proceedings of the 6th South African Rock Engineering Symposium (SARES), 12-14 May 2014, 21-33.

Sakaguchi, K., Obara, Y., Nakayama, T. and Sugawara, K. 1992. Accuracy of rock stress measurement by means of conical-ended borehole technique, J. Min. Material Process. Inst., Jpn, 108, 455-460.

Sato, N., Yabe, Y., Yamamoto, K. and Ito, H. (2003), In situ stresses near the Nojima fault estimated by deformation rate analysis (in Japanese), Zisin2, 56, 157-169.

Sugawara, K. and. Obara, Y 1999. Draft ISRM suggested method for in situ stress measurement using the compact conical-ended borehole overcoring (CCBO) technique. Int. J. Rock Mech. Min. Sci., $36,307-322$.

Van Aswegen, G. 2017. Seismic sources and rockburst damage in South Africa and Chile. Proceedings of the 9th International Symposium on Rockbursts and Seismicity in Mines (RaSiM9), Santiago, Chile.

Watson, B.P., Sellers, E.J., Kuijpers, J.S., Grave, D.M.H., Roberts, M.K.C. and Coetzer S.J. 2005. Alternative cost effective ways of determining the state of stress in mines. PlatMine report: CSIR, Division of Miningtek, Johannesburg. South Africa.

Wiles, T.2010. Map3D User's Manual, Mine Modelling Pty Ltd - www.map3d.com, Australia.

Yamamoto, K. 2009. A theory of rock core-based methods for in-situ stress measurement, Earth Planets Space, 61, 1143-1161.

Yamamoto, K., Kuwahara, Y., Kato, N. and Hirasawa, T. 1990. Deformation rate analysis: A new method for in situ stress estimation from inelastic deformation of rock samples under uni-axial compressions, Tohoku Geophys. J. (Sci. Rep. Tohoku Univ., Ser. 5), 33, 127-147.

Yabe Y., Song, S. and Wang, C. 2008. In-situ stress at the northern portion of the Chelungpu fault,Taiwan, estimated on boring cores recovered from a 2-km-deep hole of TCDP, Earth Planets Space, 60, 809-819.

Yabe, Y., Yamamoto, K., Sato, N. and Omura, K. 2010, Comparison of stress state around the Atera fault, central Japan, estimated using boring core samples and by improved hydraulic fracture tests, Earth Planets Space, 62, 257-268.

Yabe, Y. and Omura, K. 2011, In-situ stress at a site close proximity to the Gofukuji fault, central Japan, measured using drilling cores, Island Arc, 20, 160-173.

Yabe, Y., Philipp, J., Nakatani, M., Morema, G., Naoi, M., Kawakata, H., Igarashi, T., Dresen, G., Ogasawara, H., JAGUARS-Group 2009, Observation of numerous aftershocks of an Mw1.9 earthquake with an AE network installed in a deep gold mine in South Africa, Earth Planets Space, 61, e49-e52, doi:10.1186/BF03352963. 
Yabe, Y., Nakatani, M., Naoi, M., Iida, T., Satoh, T., Durrheim, R, Hofmann, G., Roberts, D., Yilmaz, H., Morema, G. and Ogasawara, H. 2013, Estimation of the stress state around the fault source of a Mw2.2 earthquake in a deep gold mine in South Africa based on borehole breakout and core discing, in Proceedings on the 6th International Symposium on In-situ Rock Stress, 20-22 August, 604613.

Zoback, M. D., Moos, D. and Mastin, L. 1985, Well bore breakouts and in situ stress, J. Geophys. Res., 90, 5523-5530.

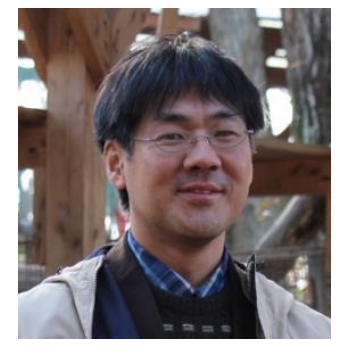

Yasuo Yabe

Associate Professor

Tohoku University

My main interest is to understand the underlying physics of earthquake generation. For this purpose, I observed microseismicity down to $\mathrm{M} \sim-4$ in earthquake prone rock mass in South African deep gold mines. Further, I have elucidated the stress state around earthquake source faults by applying some stress measurement techniques to borehole cores. 
